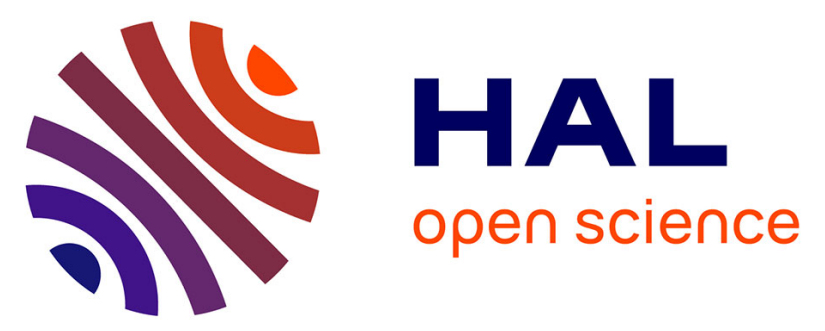

\title{
Complementarity of European RIS Territories Towards Manufacturing Educational Products
}

Panos Stavropoulos, Alexios Papacharalampopoulos, Harry Bikas, Lydia Athanasopoulou, Anna-Maria Korfiati, Christos K. Michail

\section{To cite this version:}

Panos Stavropoulos, Alexios Papacharalampopoulos, Harry Bikas, Lydia Athanasopoulou, AnnaMaria Korfiati, et al.. Complementarity of European RIS Territories Towards Manufacturing Educational Products. 22nd Working Conference on Virtual Enterprises (PRO-VE 2021), Nov 2021, Saint-Etienne, France. pp.738-747, 10.1007/978-3-030-85969-5_70 . emse-03350277

\section{HAL Id: emse-03350277}

\section{https://hal-emse.ccsd.cnrs.fr/emse-03350277}

Submitted on 25 Nov 2021

HAL is a multi-disciplinary open access archive for the deposit and dissemination of scientific research documents, whether they are published or not. The documents may come from teaching and research institutions in France or abroad, or from public or private research centers.
L'archive ouverte pluridisciplinaire $\mathbf{H A L}$, est destinée au dépôt et à la diffusion de documents scientifiques de niveau recherche, publiés ou non, émanant des établissements d'enseignement et de recherche français ou étrangers, des laboratoires publics ou privés. 


\title{
Complementarity of European RIS Territories Towards Manufacturing Educational Products
}

Panos Stavropoulos, Alexios Papacharalampopoulos, Harry Bikas, Lydia Athanasopoulou, Anna-Maria Korfiati, Christos K. Michail

Laboratory for Manufacturing Systems \& Automation (LMS), Mechanical Engineering \& Aeronautics Department, University of Patras, Patras 26504, Greece

\{pstavr, apapacharal, bikas, athanasopoulou, korfiati, michail\}@1ms.mech.upatras.gr

\begin{abstract}
Europe is in a position where the complementarity of the workforce in terms of competences and skills is able to produce a high added value for industry. The need for technologies absorption, digitalization and innovation increase dictate a change in the training products, so that every single country is benefited and utilized, simultaneously. Thus, collaborative educational and training programs can be standardized. This is a roadmap towards such a holistic design, taking advantage of the functionalities of RIS hubs that have been established in EU RIS countries. A framework of five phases is presented involving RIS hubs as well as the complementary skills of the stakeholders.
\end{abstract}

Keywords: Complementarity of skills, RIS countries, Technological areas, European innovation, Educational and training programs.

\section{Introduction}

The fourth industrial revolution (Industry 4.0), defines the new age of networked and hence digitalized manufacturing, where computers can control automated production lines with the coupling of physical and digital technologies, including technologies such as artificial intelligence, analytics, cognitive control and the internet of things (IoT) [1]. Artificial intelligence will monitor and improve the physical processes of a factory, even solving problems before they occur. A network of hub factories around the world will be controlled and upgraded remotely with little need for local human labor. This will generate abundant opportunities for new products and services, better ways to serve customers, new types of jobs and, hence, a whole new business model. B. Householder, president of Hitachi Vantara claimed that "Automation, artificial intelligence, IoT, machine learning and other advanced technologies can quickly capture and analyze a wealth of data ... Our challenge becomes moving to the next phase ... to create value from the findings obtained through advanced technologies." [2].

Recently, the European Commission (EC) has stressed the importance of the real economy and strong industry as the leading head of economic growth and employment. According to its vision, the target for the contribution of industry to GDP by 2020 has been raised to $20 \%$, i.e. reaching a value of $€ 287$ billion [3]. Currently, the European manufacturing industry is responsible for $15 \%$ of GDP [4]. 
Additionally, digitalization has diverse and opposing effects on job dynamics, on the development of new products and machines as well as on increased competitiveness. This situation creates new professional needs and these needs lead to the development of new skills, new roles and jobs or lead to the transformation of current jobs. A new type of worker known as a "knowledge worker" ("workers with higher education and characterized by knowledge work that, in turn, requires the generation and application of knowledge" [5]) is evolving, and it is no longer associated with a single work role. Therefore, many skills that aren't essential in manufacturing today will account for $1 / 3$ of the core skills in most jobs in the near future [6].

\subsection{Demand of Manufacturing Education in Europe}

It is difficult to reach the right talent with the adequate skills to fill the role since there are not enough candidates with the right skills and ethics to staff the company and in the future [7]. As the future works will be based on coding skills, it is estimated that by 2020 there will be skills shortage for 800 thousand of skilled IT jobs across the EU [8, 9]. There are about 23 million unemployed people in Europe, with 5 milling of them being young people. Simultaneously, most businesses are having difficulty finding qualified employees to fill open vacancies. It is a fact that, in the manufacturing industry, between $10 \%$ and $30 \%$ of businesses encounter increased production losses due to a shortage of highly qualified workers. It is anticipated that 80 million jobs were created in 2020, with 16 million of them requiring high-skilled staff [9].

This demand is greater for the less innovative countries (with moderate or modest innovation scores), also known as RIS (Regional innovation scheme) countries [10], such as Bulgaria, Cyprus, Greece, Spain, Lithuania, Portugal etc. that don't have a strong industrial activity and employment in their region. RIS describes the unequal geographic variation of innovation and strategies to boost regional innovation capacity. Academics illustrate the development of new path creation or the various ways of boosting the development of new activities and industries in regions to generate growth using the RIS approach [11]. It is thus important to close the huge gap between supply and demand, in other words, to close the gap between the jobs that are emerging from this radical technological development, need to be filled and talents with the skillset capable to fill industry 4.0 enabling jobs.

Thus, the question is whether there can be a common strategy for training among diversified European countries, so that innovation is accelerated. This study deals with the integration of research innovation and education activities seamlessly within a single initiative that is called Teaching Factory (TF) so as to promote the future perspective of a knowledge based competitive and sustainable manufacturing industry in RIS countries. More specifically, how stakeholders from various countries of different Innovation score can collaborate in order to create manufacturing related educational products based on the concept of TF. 


\section{Educational Areas}

To date, a number of educational initiatives are conducted aiming to grow innovation in Regional Innovation Scheme (RIS) countries while increasing the know-how transfer and enhancing the innovation capacity in industrial partners (startups, scale-ups, OEMs) and higher education institutions. Also, collaborations such as EIT-RIS aim at the partnerships of higher education institutions, research organization, industries and others partners in the Knowledge and Innovation Communities (KICs) activities, creating the right foundations. Depending on the regional preference, different specialization among with the Information and Communication Technology (ICT), logistics, industry, energy, environment and sustainability, etc. can be selected by the firm's field [10]. All over industrial applications, integration of ICT technologies seems to be the most relevant strategy. For instance, Greece develops a resistance spot welding testbed targeting on the Cognitive Automation of the process. Another RIS country, Czech Republic, completes a robotic assembly line, a 5-axis milling workstation and a milling robot testbed for research, demonstration and learning of those processes (details are given in the Appendix).

Additionally, Research and Innovation Strategies for Smart Specialization (RIS3), referring to the national/regional economic transformation, are based on five key aspects [12]: i) policy support and investments, ii) enhance national/regional strengths, iii) trigger private sector investments, iv) boost stakeholders, v) evidence-based systems. The vital goals of RIS3 consist from the smart, sustainable and inclusive growth applying on the research, technological development \& innovation (RTDI) and ICT [13]. RIS3 also promote the growth of jobs and industries across RIS countries.

RIS and RIS3 are providing the appropriate emergent skills gaps on numerous education areas on the added-value manufacturing. The education area may be tentatively classified in (a) Innovation strategy, (b) Digitalization of manufacturing systems and processes, (c) Emergent technologies in manufacturing, (d) Advanced monitoring and control systems, (e) Cognitive Automation, (f) Digital Twins, (g) Advanced ICTs, (h) Intellectual Property Rights and Security Issues (targeting CEO/executives), (i) Sustainable manufacturing, (h) Digital skills (CAx).

\section{Framework for Orchestrating Educational Design}

An educational framework design has to take into account all the factors affecting its operation and the sustainability. Therefore, the Knowledge Triangle Integration (Education, Innovation, Business Creation) has to be taken into account, and the wellestablished concept of RIS Hubs [14] can be used to this end, gathering all the basic information needed for this work, such as regional capabilities and needs, technologies offered, as well as partnerships.

Additionally, the concepts of evaluation, certification and communication are vital to the sustainability of such programs and frameworks, guaranteeing their usability and the smooth operation. Additionally, the link to non-RIS countries is also vital, rendering the exchange of technical and monetary flows possible, through networking and establishing information flows and the corresponding value chains. 
The following schematic (Fig. 1) is indicative of the flow of information needed to design such frameworks. It is separated in five phases; design, preparation, pilots, evaluation, operation and communication, rendering its implementation a feasible target. The Teaching Factory (TF) paradigm [15] is located at the core, integrating personalized experiential learning and reducing the needs for evaluation extra steps.

The Teaching Factory paradigm can be used as a medium of experiential education. When implemented at a network level (involving and connecting multiple industrial and academic actors), the TF paradigm can bring together diverse competences, backgrounds and know-how, enabling the effective exchange of knowledge between them. The network facilitates the launch of collaborative manufacturing training projects with mutual interest. Participating organizations can effectively exchange information, including teaching material, virtual access to state-of-art infrastructure (including Learning Factories (LF) [16]), real industrial challenges and novel solutions. These organizations are classified into two boards. On one hand, the academic board focuses on providing novel concepts, approaches, and remotely-accessed test-beds to address both industrial needs and innovative educational schemes. On the other hand, the industrial board has the chance to express their needs in terms of training and upskilling personnel as well as provide a number of industrial challenges to be elaborated by the developed network. Evidently, stakeholders in both boards can originate from different countries, creating thus an adequately diversified skills spectrum in order for the training to be holistic

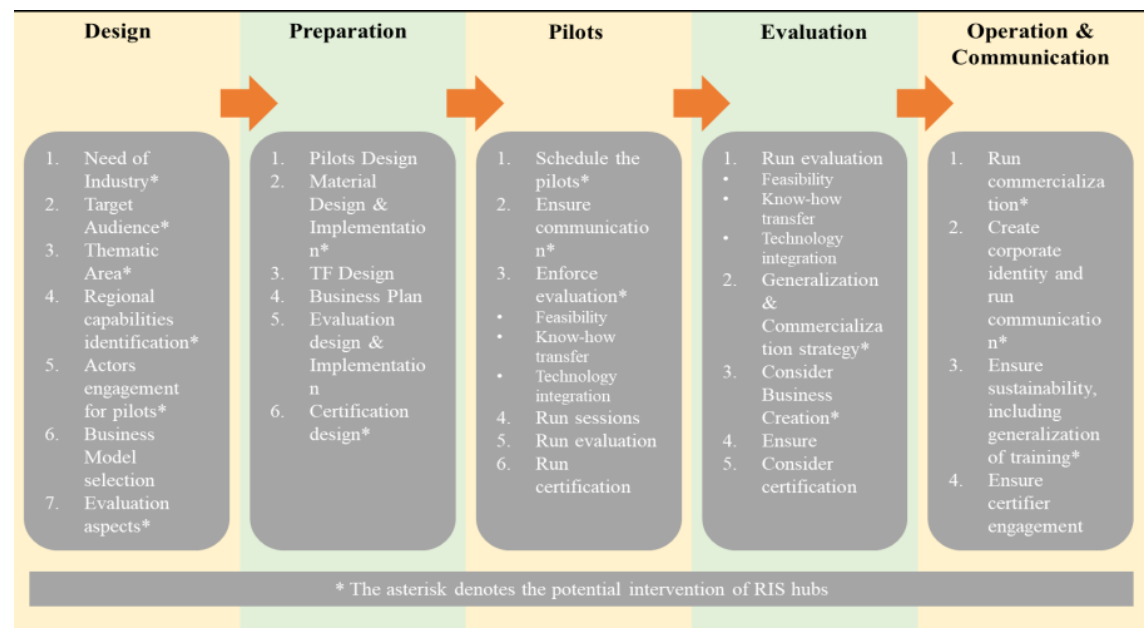

Fig. 1. Phases of implementing a complete manufacturing educational program based on collaboration between RIS countries.

As such, a TF can operate in multiple knowledge transfer modes. "Industry-toacademia" aims at transferring the real manufacturing environment to the classroom through the adoption of an industrial project involving one factory in a simultaneous interaction with one or several classrooms. This interaction can involve discussions, presentations, live videos from the production, and other knowledge delivery 
mechanisms. A characteristic example would be solving an industrial challenge, where different entities could focus on different aspects of it (such as mechanical design, mechatronics, electronics, software, HMI, and business-related aspects). Similarly, benefits arise when industrial actors from different industrial sectors openly present their challenges and innovative solutions, best practices or success stories, fostering innovation in other industries ("industry to industry"). Finally, "academia-toindustry" aims at transferring knowledge from academia to industry. Test-beds and demonstrators for new technological concepts are installed into academic facilities (Learning Factories) in order to be validated by students and researchers or used for professionals training and upskilling.

As an example, the aim of ManuLearn project has been to "to enhance the innovation capacity of the participating EIT RIS countries by improving their educational framework and by boosting their digital capabilities in order to face the future manufacturing challenges". Therefore, different stakeholders from industry and academia can work together to manually develop their skills through co created solutions to real manufacturing problems combining the concepts of Teaching and Learning factories.

Additionally, the main goal of the ShapiNG I project has been to motivate and raise the interest of young Europeans, with particular emphasis on high school students (ages 15-18) and with a special focus on females, for activities in the field of manufacturing, within Portugal, Spain, Greece, and Slovakia. In particular, the aim of the "3D Printing for Pupils" TF has been to engage pupils with a simple Additive Manufacturing concept while helping them gain practical skills and knowledge about designing spare parts and developing skills related to problem solving, decision making, creativity and teamwork. Thus, activities could be also extended to secondary education and to a broader audience including high school students, overcoming the fact that high school students may have limited involvement with the real production environment and the manufacturing processes and technologies.

\subsection{Design of Business Plan}

Education-as-a-Service (EaaS) use cloud-enabled business models for teaching or/and training purposes such as assignments, support, lectures, further reading material, video demonstration etc. [17]. Internet and cloud-based services comprise the enablers for the "Education-as-a-Service" [18]. The conventional/traditional educational programs targeting on static curriculum per course. The EaaS scheme focused on the dynamic added-value knowledge in emergent topics in each field. The online education business models mainly focus on the profitability of the services through four financial approaches $[19,20]$, i) the charge of certifications/badges, ii) the charge of extended services (documents, demo, etc.), iii) the link of students to potential employers, iv) and last the advertisements. To date, educational business models profiting from the above services are referring to Massive Open Online Courses (MOOCs) and it's free for access [21]. For instance, three major academic-oriented educational platforms are Coursera [22], edX [23] and Khan Academy [24] which close collaborate with top universities and institutes. The number of registrations on these platforms are increasing, however the completion is relative low and the drop-out rate reaches 85-95 
$\%$ [25]. The hot-topic of Artificial Intelligence (AI) occurred only a $17.5 \%$ completion rate. Another way of educational scheme is the "blended course scheme" which assist the conventional curriculum with virtual courses with the appropriate credits. Now, both Coursera and edX are offering more advanced course in post-graduate level, which does not require any application form, but typically cost approximately from 1,000 to $5,000 \$[26]$.

In manufacturing engineering, no specialized holistic approach of educational and training platform exists on the market. Hence, a business plan on highly added-value manufacturing (AVM) is proposed for the developing of a unique educational platform based on emergent technologies, tools and techniques, both theoretical and practical with the use of testbeds [27]. Manufacturing engineering-oriented educational platform is targeting on executives and professional engineers for up/re-skill in RIS/RIS3 countries.

The business model referring on the conceptual framework, while the business plan to the documenting strategy of the project's targets [28]. At the starting point of the training material design, a business model CANVAS is needed to establish all the key components including cost-related factors. Afterwards, a SWOT-PESTEL analysis is to be performed to determine the key factors of the business plan. At the end of the design, a VRIO analysis has to be performed to uncover any competitive advantages of the platform. The EaaS scheme is used to enhance the accessibility of the courses through cloud-based services.

\section{Conclusions and Future Outlook}

It is evident that RIS countries' complementarity can be utilized towards forming proper educational frameworks as well as education material, aiming simultaneously towards (i) technology integration in manufacturing enterprises, (ii) training engineers and operators on these technologies and (iii) educating students and pupils on manufacturing cutting-edge technologies. To this end, the orchestration of such activities should be performed by one framework, taking into account the role of RIS Hubs. The variability in the background of the involved stakeholders seems to be sufficiently large in order to meet the needs of continuously evolving European Industry, addressing the need for further innovation absorption and digitalization.

The details of the preparation lie on the fact that everything should be based on regional needs and capabilities, thus forming even temporary local networks between actors from such regions. Then, evaluation, communication as well as commercialization strategies need to be involved.

For the future activities, the technical areas need to be harmonized, in a formal and structured way, as well as the skills and competencies need to be addressed explicitly through this framework. The way to achieve these is making sure everyone is confident in themselves being engaged with proper evaluation methods. Also, the evaluation of the framework in terms of applicability ought to be formulated and evaluated; this will have to be performed in a twofold way; firstly, with respect to upskilling (knowledge) 
workers and secondly concerning technology absorption and innovation enhancement as foreseen [29].

\section{Acknowledgements}

The formation of the current framework has been funded by EIT Manufacturing project "EIT Manufacturing RIS Hubs".

\section{References}

1. Industrie $4.0 \quad$ site, https:/www.plattformi40.de/PI40/Navigation/EN/Industrie40/WhatIsIndustrie40/what-is-industrie40.html (2021)

2. Deloitte: The Fourth Industrial Revolution is here: are you ready? https://www2.deloitte.com/cn/en/pages/consumer-industrial-products/articles/industry-4-0technology-manufacturing-revolution.html (2018)

3. Alessandrini, M., Celotti, P., Gramillano, A., Lilla, M.: The future of industry in Europe. Brussels: European Committee of the Regions (2017)

4. World bank data, https://data.worldbank.org/indicator/NV.IND.MANF.ZS?locations=EU

5. Razzaq, S., Shujahat, M., Hussain, S., Nawaz, F., Wang, M., Ali, M., Tehseen, S.: Knowledge management, organizational commitment and knowledge-worker performance. Business process management journal (2019)

6. Aulbur, W., Arvind, C.J., Bigghe, R.: Whitepaper: Skill Development for Industry 4.0. BRICS Skill Development Group: Roland Berger (2016)

7. Deloitte Insights: Deloitte skills gap and future of work in manufacturing study (2018)

8. The Guardian: Rise of The Machines: Why Coding is the Skill you Have to Learn. https://www.theguardian.com/new-faces-of-tech/2018/oct/25/riseof-the-machines-whycoding-is-the-skill-you-have-to-learn (2018)

9. Bert Maes: The future of European Education and training System. https://bertmaes.wordpress.com/report-skills-shortage/, accessed 20/06/2021

10.European Institute of Innovation \& Technology (EIT): EIT Regional Innovation Scheme. https://eit.europa.eu/our-activities/eit-regional-innovation-scheme-ris (2019). Accessed 10 April 2021

11.Hervas-Oliver, J.L., Gonzalez-Alcaidem G., Rojas-Alvarado, R., Monto-Mompo, S.: Emerging regional innovation policies for industry 4.0: analyzing the digital innovation hub program in European regions. Competitiveness Review: An International Business Journal (2020)

12.Foray, D., Goddard, J., Beldarrain, X.G., Landabaso, M., McCann, P., Morgan, K., Nauwelaers, C., Ortega-Argilés, R.: Guide to research and innovation strategies for smart specialisations (2012)

13.João Lopes, João J. Ferreira, Luís Farinha: Innovation strategies for smart specialisation (RIS3): Past, present and future research. Growth and Change (2019)

15.EIT Manufacturing RIS Hubs site, https://eitmanufacturing.eu/eit-manufacturing-ris-hubs/, accessed 27/04/2021

16.Chryssolouris, G., Mavrikios, D., Rentzos, L.: The teaching factory: a manufacturing education paradigm. Procedia CIRP 57, 44-48 (2016).

16.Abele, E., Metternich, J., Tisch, M., Chryssolouris, et al: Learning factories for research, education, and training. Procedia CIRP 32, 1-6 (2015). 
17.Prifti, L., Knigge, M., Löffler, A., Hecht, S., Krcmar, H.: Emerging Business Models in Education Provisioning: A Case Study on Providing Learning Support as Education-as-aService. Int. J. Eng. Ped. (2017)

18.Deepa, N., Sathiyaseelan, R.: The Cloud and the Changing Shape of Education - Eaas (Education as a Service). International Journal of Computer Applications 42, 4-8 (2012)

19.Okoli, C., Wang, N.: Business Models for Online Education and Open Educational Resources. SSRN Working Paper Series (2016)

20.Burd, E.L., Smith, S.P., Reisman, S.: Exploring Business Models for MOOCs in Higher Education. Innov High Educ (2015)

21.Long, Y.: Explore the Business Model of MOOCs. International Conference on HCI in Business, Government, and Organizations, 181-193 (2017)

22.Coursera. https://www.coursera.org/. Accessed 4 April 2021

23.edX. https://www.edx.org/. Accessed 4 April 2021

24.Khan Academy. https://www.khanacademy.org/. Accessed 4 April 2021

25.Leighton, M.: edX MicroMasters vs Coursera MasterTracks comparison and FAQ. https://www.businessinsider.com/edx-micromaster-vs-coursera-mastertrack-online-mastersprograms (2021). Accessed 13 April 2021

26.Chryssolouris, G., Mavrikios, D., Rentzos, L.: The Teaching Factory: A Manufacturing Education Paradigm. Procedia CIRP 57, 44-48 (2016)

27.Teece, D.J.: Business Models, Business Strategy and Innovation. Long Range Planning (2010)

28.Kalman, Y.M.: A race to the bottom: MOOCs and higher education business models. Open Learning: The Journal of Open, Distance and e-Learning (2014)

29.Thalheimer, W.: The learning-transfer evaluation model: Sending messages to enable learning effectiveness. https://www.worklearning.com/wp-content/uploads/2018/02/Thalheimer-TheLearning-Transfer-Evaluation-Model-Report-for-LTEM-v11.pdf (2018). Accessed 15 April 2021 


\section{Appendix}

Material from the projects below has been taken, as they complete each other with respect to the goals of the current work.

Table 1. Concepts adopted from various educational projects.

\begin{tabular}{llll}
\hline Projects & Carrier & Concepts & Running period \\
\hline TF KnowNet & EIT Manufacturing & Learning-Transfer Evaluation Model & Jan. 2020-Dec. 2020 \\
Manulearn & EIT Manufacturing & Academia - Industry TF & As above \\
M-NEST-RIS & EIT Manufacturing & Evaluation, Cognitive Control LF & As above \\
Shaping I & EIT Manufacturing & Industry - Pupils TF & As above \\
InMas & EIT Manufacturing & Workshops to pupils & As above \\
M-NEST-II & EIT Manufacturing & Business Model & Jan. 2021-Dec. 2021 \\
\hline
\end{tabular}

